\title{
ACHADO ARQUEOLÓGICO NA PONTE BINACIONAL: REFLEXÕES SOBRE AS FRAGILIDADES DA PROTEÇÃO DO PATRIMÔNIO AMBIENTAL CULTURAL ${ }^{1}$
}

\author{
ARCHAEOLOGICAL FIND IN BINACIONAL BRIDGE: REFLECTIONS ON THE \\ WEAKNESSES OF THE PROTECTION OF CULTURAL HERITAGE ENVIRONMENTAL
}

Ana Cristina Rocha Silva ${ }^{2}$

http://lattes.cnpq.br/1459668482119185

Célia Souza da Costa 3

http://lattes.cnpq.br/6191102948827404

Elivaldo Serrão Custódio 4

http://lattes.cnpq.br/8819683729192070

https://orcid.org/0000-0002-2947-5347

Artigo recebido em 12/03/2016

Aceito para publicação em 25/12/2019

\begin{abstract}
RESUMO: O presente artigo trata de reflexões referentes às fragilidades observadas no trato do patrimônio ambiental cultural em meio a grandes projetos de infraestrutura. Tais reflexões partem da paralisação das obras da Ponte Binacional, que liga o Brasil à Guiana Francesa, em agosto de 2009, em virtude da existência de um sítio arqueológico na área de afetação do empreendimento. A Constituição Federal de 1988 inovou ao incluir todos os sítios arqueológicos à lista de bens da União, estendendo a tutela legal não apenas para os sítios já registrados, como também para aqueles ainda não identificados. Por essa razão é que qualquer projeto que implicará na alteração do uso do solo deve fazer, em meios aos inúmeros estudos quem compõem o EIA/RIMA, o estudo arqueológico. Contudo, embora a proteção legal ao patrimônio cultural em questão seja prevista na legislação brasileira, ainda é possível observarmos descompassos quando a proteção desses bens ambientais culturais se depara com projetos de infraestrutura que carregam carga significativa de interesses econômicos e políticos.
\end{abstract}

${ }^{1}$ O presente trabalho foi realizado com apoio da Coordenação de Aperfeiçoamento de Pessoal de Nível Superior - Brasil (CAPES) - Código de Financiamento 001.

2 Doutoranda em Ciências: Desenvolvimento Socioambiental pelo Programa de Pós-Graduação em Desenvolvimento Sustentável do Trópico Úmido, do Núcleo de Altos Estudos Amazônicos da Universidade Federal do Pará (PPGDSTU/NAEA/UFPA). Mestre em Direito Ambiental e Políticas Públicas pela Universidade Federal do Amapá. Historiadora e Professora Assistente II do Curso de Licenciatura em História da Universidade Federal do Amapá. Bolsista CAPES. E-mail: tinastn@hotmail.com

${ }^{3}$ Doutoranda em Educação pela Pontifícia Universidade Católica do Paraná - PUC/PR. Mestre em Direito Ambiental e Políticas Públicas pela Universidade Federal do Amapá. Professora do Instituto Federal do Amapá. E-mail: celia.amapa@hotmail.com

${ }^{4}$ Pós-Doutor em Educação pela Universidade Federal do Amapá (UNIFAP). Doutor em Teologia pela Faculdades EST em São Leopoldo/RS, Brasil. Atualmente é Professor Permanente no Mestrado em Educação (PPGED/UNIFAP). Membro do Grupo de Pesquisa Educação, Relações Étnico-raciais e Interculturais (UNIFAP/CNPq). E-mail: elivaldo.pa@hotmail.com 
Defenderemos aqui a idéia de Silva (2007), quando esta afirma que a preservação patrimonial não se faz somente com aplicação de leis. As regras ligadas à preservação arqueológica se inserem num quadro muito mais amplo de políticas públicas que devem ser fundamentadas nas reivindicações da sociedade.

Palavras-chave: Ponte Binacional; Patrimônio cultural; Projetos de infraestrutura; Proteção patrimonial.; Amapá.

ABSTRACT: This article deals with reflections on the weaknesses observed in the treatment of cultural environmental heritage in the midst of major infrastructure projects. These reflections are based on the finding of archaeological site found in the Binational Bridge in August 2009, the city of Oiapoque-AP. The Federal Constitution of 1988 broke new ground by including all archaeological sites to the list of goods of the Union, extending the legal protection not only for sites already recorded, but also for those not yet identified. For this reason is that any project that will involve changes in land use, must, in many ways to those studies comprise the EIS / EIR, the archaeological study. However, although the legal protection of cultural heritage in question is provided in our Constitution, it is still possible to observe mismatches when the protection of environmental assets are faced with cultural infrastructure projects that carry significant burden of economic and political interests. Defend here the idea of Silva as it claims that heritage preservation is not only with law enforcement. The rules relating to archaeological preservation are part of a much broader framework of policies that must be grounded in claims of the collectivity of society.

Keywords: Binational Bridge. Cultural heritage. Infrastructure projects. Asset protection. Amapá.

\section{INTRODUÇÃO}

A Constituição Federal de 1988 ofertou mudanças significativas ao conceito de patrimônio cultural. Antes reduzido aos monumentos e produção cultural da elite dominante, a partir de 1988, o conceito passou a evocar o conjunto dos bens culturais (materiais e imateriais) referentes às identidades coletivas. Indo além, os bens culturais foram inclusos ao entendimento de meio ambiente, constituindo-se bens ambientais tutelados por legislação específica.

Nesse novo contexto, o patrimônio cultural não se desvincula do meio ambiente, uma vez que é em meio ao ambiente que o homem produz cultura. Assim, de acordo com Soares (2007), o meio ambiente é um macrobem uno, composto por elementos naturais e culturais que são essenciais para a promoção da dignidade da pessoa humana. Partindo desse entendimento, Leite (1998) evidencia que o macrobem denominado meio ambiente é composto por elementos corpóreos e incorpóreos que possuem conceituação e regime próprios. Eles podem ser: florestas, flora, água, mineração, garimpo, caça, energia nuclear, patrimônio cultural, patrimônio arqueológico, dentre outros.

Entendido como elemento do meio ambiente, o patrimônio cultural é também um direito fundamental difuso (grifo dos autores), pois "[...] pertence a todos ao mesmo tempo em que não pertence, de forma individualizada, a qualquer pessoa” (MIRANDA, 2006, p. 17).

Logo, a proteção do meio ambiente (latu sensu) - no qual está incluso o patrimônio cultural - não deve ser "[...] tratada em função do interesse exclusivo da geração presente, mas sim em função de outros valores importantes para a manutenção da humanidade na Terra"

PRACS: Revista Eletrônica de Humanidades do Curso de Ciências Sociais da UNIFAP 
(SOARES; FARIAS, 2018, p. 150).

Embora a interdependência entre o meio ambiente cultural e o meio ambiente natural seja tema passivo na literatura especializada, não raro as problemáticas ambientais descuidam-se dos aspectos culturais do meio ambiente. Em vista disso, quando diante de atividades potencialmente degradodoras ao meio ambiente, em geral, priorizam-se ações de resguardo aos elementos naturais, de modo que os elementos culturais são negligenciados. Assim, a pensar-se com Caldarelli (1993, p. 264), mesmo que o patrimônio cultural seja "[...] parte integrante e indissociável do meio ambiente [...]”, com frequência ele é esquecido nos procedimentos concernentes a estudos de impacto ambiental. Situação que denota o "[...] descuido dos órgãos públicos responsáveis pela política ambiental nas diversas esferas institucionais do país”. (CALDARELLI, 1993, p. 258).

Em agosto de 2009, o "descuido" evidenciado por Caldarelli (1993, p. 258) pôs em risco iminente o patrimônio cultural arqueológico situado em território amapaense. Referimo-nos ao sítio arqueológico existente na área de afetação da Ponte Binacional, no município de Oiapoque, estado do Amapá, Brasil.

A despeito da exigência do estudo arqueológico no processo de Licenciamento Ambiental do referido empreendimento estrutural, as obras da ponte iniciaram sem a execução obrigatória de todas as ações concernentes às etapas do estudo arqueológico que integra o Estudo de Impacto Ambiental (EIA) do empreendimento. Procedimento este que provocou a interdição da obra, conforme noticiou a mídia na época. Adiante, destaca-se um trecho de uma das inúmeras matérias veiculadas nos meios de comunicação a respeito da interdição da obra em questão:

O Instituto Brasileiro do Meio Ambiente (Ibama/AP) divulgou hoje (17) que, na última sextafeira (14), paralisou a obra da Ponte Binacional, que ligará o município Oiapoque a Guiana Francesa (FRA). Ação do Ibama atendeu a um pedido do Instituto do Patrimônio Histórico e Artístico Nacional (Iphan/AP), que afirmou que existem sítios arqueológicos em torno da construção. O Governo do Amapá (GEA) declarou que tentará resolver o problema com a direção do Iphan e enviará uma equipe de pesquisadores do Instituto de Pesquisas Científicas e Tecnológicas do Estado do Amapá (Iepa) ao local, para uma visita ao canteiro de obras da Ponte. -Temos interesse na preservação e resgate de todo e qualquer patrimônio histórico do Amapá, mas o Estado precisa, o mais rápido possível, da execução da obra. Tentaremos evitar que a paralisação demore e que os serviços sejam continuados, afirmou o secretario especial de governadoria, Alberto Góes (PORTAL SIPAM, 2009).

Sobre o conteúdo da notícia destacada, observa-se que ele transmite muito mais do que a informação da paralização das obras na Ponte Binacional. Ao evidenciar a "urgência" na execução da obra, a notícia revela a fragilidade da proteção dos bens culturais diante de projetos de insfraestrutura com carga elevada de interesses políticos e econômicos.

Há de se destacar, ainda, que os estudos arqueológicos preliminares que compuseram as etapas iniciais do licenciamento da obra, constataram e informaram ao DNIT, ainda em janeiro de 2008, que o local do empreendimento possuía alto potencial para a ocorrência de sítios arqueológicos. Logo, ao que tudo indica, o Estado arriscou-se em iniciar as obras de um dos empreendimentos de maior referência no cenário político e sócio econômico atual do Amapá, já sabendo da possibilidade de existência de sítios arqueológicos no lugar. O que, por sua vez, sinaliza a arbitrariedade para com a legislação brasileira, que confere uma prote- 
ção qualificada ao patrimônio arqueológico, por meio de inúmeros instrumentos legais.

Isto posto, o caso do sítio arqueológico da ponte Binacional, que liga o Brasil à Guiana Francesa, será utilizado aqui para propor reflexões acerca das fragilidades que envolvem o cumprimento da legislação de proteção ao patrimônio arqueológico. Para tanto, adiante apresentam-se: i) discussões acerca da importância da preservação do patrimônio arqueológico na Amazônia; ii) a síntese dos principais instrumentos legais de proteção do patrimônio arqueológico; iii) a contextualização do caso envolvendo o sítio arqueológico da ponte Binacional, localizando, neste ponto, os desafios da educação patrimonial na gestão do patrimônio arqueológico; por fim, faz-se as considerações finais.

É necessário esclarecer que os estudos do sítio arqueológico na área da Ponte Binacional ainda estão em andamento. Dessa maneira, as reflexões aqui realizadas partem de informações veiculadas nos meios de comunicação, de informações obtidas no Núcleo de Pesquisas Arqueológicas do Instituto de Pesquisas Científicas e Tecnológicas do Amapá (NUPArq/IEPA) e no Instituto do Patrimônio Histórico e Artístico Nacional, seção Amapá (IPHAN/AP), bem como da análise de dados contidos no Relatório de Campo do Programa Arqueológico de Prospecção, Resgate e Educação Patrimonial da Ponte Internacional sobre o Rio Oiapoque/AP, cedido aos autores pelo NUPArq/IEPA.

\section{A IMPORTÂNCIA DA PROTEÇÃO DO PATRIMÔNIO ARQUEOLÓGI- CO NA AMAZÔNIA}

Outrora considerada um ambiente pobre e inibidor ao desenvolvimento cultural (MEGGERS, 1987), estudos arqueológicos indicam que a Amazônia é ocupada há, no mínimo, 11.200 anos $\mathrm{AP}^{5}$ (ROOSEVELT, 1992), com casos de populações que chegaram a atingir o quantitativo de milhares de pessoas (NEVES, 2006). Nessa direção, contrariando teorias que subestimavam o potencial cultural da região, a pesquisa arqueológica tem indicado que a Amazônia não foi " [...] hostil à presença do ser humano. A vida na floresta nunca foi fácil, mas há milhares de anos o homem aprendeu a se estabelecer na mata e nela desenvolveu sociedades complexas" (NUNES FILHO, 2011, p. 102). Logo, tais grupos foram capazes de manter "[...] uma relação harmoniosa com o ecossistema Amazônico e uma preocupação com a preservação ambiental” (NUNES FILHO, 2011, p. 99).

Nesses termos, a partir da diversidade e especialização de recursos ambientais, os povos antigos da Amazônia “[...] superaram a barreira do tempo em termos de modernidade e inovação tecnológica sem agredir o ambiente natural” (NUNES FILHO, 2011, p. 99). Ao agir de tal modo, se tem no estudo Nunes Filho (2011) evidências concretas da contribuição humana para diversificação dos recursos ambientais na região. Contribuição essa que, inclusive, já fora consagrada nos estudos de Balée (1989). Apesar da importância de dados como estes para a (re)escrita da história da Amazônia e de seus povos, ainda hoje, a região é equivocadamente apresentada "[...] como uma das últimas fronteiras inexploradas do planeta, um exemplo de natureza primordial, intocada pela ação humana desde o início dos tempos" (NEVES, 2006, p. 7).

A perpetuação de tal mito, construído principalmente a partir do imaginário europeu durante a Conquista, direcionou para a humanidade da Amazônia o rótulo de "[...] intrusa impertinente [...]" (AMARAL et al, 2011, p. 9), de modo que, conforme indicam Simonian e

5 Antes do presente.

PRACS: Revista Eletrônica de Humanidades do Curso de Ciências Sociais da UNIFAP 
Baptista (2015), nos inúmeros projetos de desenvolvimento criados para a região, a humanidade local e seus respectivos modos de viver têm sido negligenciados. Por sua vez, historicamente, isso tem se revertido em insustentabilidades nos aspectos humano e social, em movimentos de desterritorialização, retorritorialização e reorganização social que atingem e modificam fortemente os modos de vida de povos indígenas, de populações tradicionais, dentre outros coletivos locais por toda a região.

Isto posto, há de se reconhecer que a pesquisa científica - incluindo a arqueológica - não é importante apenas para o (re)conhecimento da história da Amazônia, ela é, igualmente, fundamental para a construção de políticas públicas consonantes com a sociodiversidade da região e seus múltiplos modos de viver. Em se tratando da produção de conhecimento a respeito dos povos antigos da região, a arqueologia ganha centralidade nesta tarefa, uma vez que "[...] é a ciência que estuda as sociedades humanas passadas através de seus vestígios materiais” (BARRETO, 2010, p. 16). Todavia, na Amazônia, a produção científica advinda da arqueologia possui complicadores que vão desde o clima ${ }^{6}$ até as grandes obras de infraestrutura que, ao revolverem o solo, destroem tanto com os sítios arqueológicos, como também com a possibilidade de realização de estudos científicos sobre os mesmos.

Desse modo, entende-se que esgotadas as possibilidades de investigação científica de um sítio arqueológico, por consequência, tira-se das presentes e futuras gerações o direito de compreensão de seu passado. Reforçar-se, direito este que é garantido a todos pelo Estado brasileiro, por meio do art. 215 da CF/1988, o qual prevê que “[...] o Estado garantirá a todos o pleno exercício dos direitos culturais e acesso às fontes da cultura nacional [...]” (BRASIL, 1988). Tendo em vista esse aspecto legal, procedimentos como o adotado no caso da Ponte Binacional - em que o Estado, à revelia das informações contidas no EIA, aparentemente ignorou a possibilidade de existência de sítios arqueológicos na área - são extremamente preocupantes, uma vez que seguem na contramão do que regem os instrumentos legais de proteção.

\section{A PROTEÇÃo LEGAL do PATRIMÔNIO ARQUEOLÓGICO}

Com base na Carta de Lausanne, documento internacional que orienta a proteção e gestão do patrimônio arqueológico, esse tipo patrimônio constitui:

[...] a porção do patrimônio material para a qual os métodos da arqueologia fornecem os conhecimentos primários. Engloba todos os vestígios da existência humana e interessa todos os lugares onde há indícios de atividades humanas não importando quais sejam elas, estruturais e vestígios abandonados de todo o tipo, na superfície, no subsolo ou sob as águas, assim como o material a eles associados (ICOMOS, 1990).

A partir da definição ofertada, consideram-se vestígios arqueológicos todos os indícios da presença ou ação humana situados em um determinado espaço. De acordo com Soares (2007), a característica principal do patrimônio arqueológico é a finitude de sua base de dados, razão pela qual o Estado deve atuar de modo eficiente para garantir a sua preservação e proteção. Portanto, conforme a autora, a possibilidade de finitude dos bens arqueológicos é o que justifica a intervenção do Poder Público quando este patrimônio possui ameaça de

6 A umidade da Amazônia é um dos fatores que limita a durabilidade de artefatos arqueológicos. 
dano.

No Brasil, a União é a titular dos direitos (reais ou pessoais) sobre o patrimônio arqueológico. Destarte, segundo Soares (2007), os bens arqueológicos se configuram como bens de interesse público e, além de supraindividual, sua tutela é intermediada por pessoa jurídica de direito público, a saber: o Instituto do Patrimônio Histórico e Artístico Nacional (IPHAN). Explica Soares (2007) que, por serem bens públicos e de interesse público, a própria relação do Poder Público para com este bem é diferente.

Desse modo, a finalidade da gestão pública do patrimônio arqueológico “[...] nunca será ser a de geração de recursos financeiros [...]" (SOARES, 2007, p. 57), ainda que ele possua valor econômico. Isso se justifica porque a função específica do bem em tela é a "[...] produção de conhecimento sobre o passado humano e para a compreensão da existência humana" (SOARES, 2007, p. 57).

$\mathrm{Na}$ condição de bens da União e conforme Soares (2007), a fruição do patrimônio arqueológico deve ser realizada em consonância com o interesse da coletividade. Logo, no trato dos bens arqueológicos, o Poder Público é obrigado a atuar no sentido viabilizar o conhecimento, a organização e a proteção dos mesmos. "Cabe ao Estado a tarefa de dar efetividade ao direito da sociedade de ter os bens de valor cultural protegidos e preservados" (SOARES, 2007, p. 58).

Em face da importância do patrimônio arqueológico para a compreensão da cultura nacional, essa modalidade de bem cultural já possui a tutela do Estado desde o ano de 1937, por meio do Decreto Lei no 25/1937. Contudo, esse instrumento legal restringia a proteção aos sítios arqueológicos com características excepcionais, ficando sem proteção de cunho legal aqueles com menor exuberância e monumentalidade. Nos termos de Silva (2007), isso se modifica em 1961, ano em que Juscelino Kubitschek é substituído por Jânio Quadros. Nesse contexto, ocorre forte pressão para a criação de um instrumento legal que conferisse proteção a todos os sítios arqueológicos, sejam eles excepcionais ou não.

Então, é criada a Lei Federal no 3.924/1961, conhecida como a primeira legislação referente à proteção do patrimônio arqueológico no Brasil. A Lei no 3.924/1961 estabelece que os monumentos arqueológicos e pré-históricos existentes no território nacional, bem como todos os elementos que neles se encontram, ficam sob a guarda e proteção legal do poder público. Segundo Soares (2007), a referida lei espelha os valores e as diretrizes para a gestão dos bens arqueológicos, indicando as possibilidades e os limites de atuação da Administração Pública e da sociedade na matéria.

Para Soares (2007, p. 68), a Lei no 3.924/1961 ofertou um tratamento autônomo ao patrimônio arqueológico nacional, bem como estabeleceu restrições e parâmetros para atividades econômicas que de algum modo ofertem perigo à integridade física dos bens arqueológicos. Nas décadas seguintes, com um cenário jurídico oportuno e sob a influência da Conferência das Nações Unidas para o Meio Ambiente, realizada em 1972, em Estocolmo, bem como da Convenção para a Proteção do Patrimônio Cultural e Natural Mundial, é promulgada no Brasil a Lei de Política Nacional de Meio Ambiente (Lei no 6.938/1981).

Nos termos de Soares e Farias (2018), essa lei permitiu a estruturação de um sistema de proteção ambiental, no qual a relação entre atividade econômica e meio ambiente passou a ser disciplinada por regras que estabelecem mecanismos e obrigações para o Poder Público. A Lei no 6.938/1981 recepcionou a concepção jurídica de meio ambiente como um macrobem e, indo além, instituiu o Sistema Nacional do Meio Ambiente (SISNAMA) e o Conse-

PRACS: Revista Eletrônica de Humanidades do Curso de Ciências Sociais da UNIFAP 
lho Nacional do Meio Ambiente (CONAMA). Como consequência dessas ações, todos os elementos que integram o meio ambiente (inclusive os culturais) foram integrados ao sistema de proteção ambiental (SOARES; FARIAS, 2018).

A partir de então, nos processos de licenciamento ambiental, se tem a obrigatoriedade de contemplação da vertente cultural nos procedimentos de análise da viabilidade do empreendimento. Análises estas que se dão por meio do Estudo de Impacto Ambiental e do Relatório de Impacto Ambiental (EIA/RIMA). Ao ter-se em vista a consideração do patrimônio arqueológico nesse processo, a Resolução CONAMA n ${ }^{\circ}$ 01/1986 previu a inserção do estudo arqueológico aos estudos que compõem o licenciamento ambiental de qualquer espaço a ser afetado por um empreendimento potencialmente impactante. O objetivo central dessa resolução é a identificação das variáveis culturais e a garantia do pleno exercício dos direitos culturais estabelecido pelo artigo 215 da CF/1988 a todos os cidadãos.

De acordo com Soares e Farias (2018), as leis ambientais possuem um pilar protetivo e repressivo mais firme, uma vez que contam com um aparelhamento normativo mais efetivo no que diz respeito à responsabilização daqueles que ocasionam "[...] danos aos bens ambientais, com a previsão de responsabilidade objetiva no âmbito cível e da responsabilidade penal da pessoa jurídica" (SOARES; FARIAS, 2018, p. 150). Ademais, conforme os autores, no que tange ao patrimônio arqueológico, os princípios ambientais já estão consolidados na jurisprudência brasileira, o que facilita uma comunicação com o judiciário, nos casos de danos a esse tipo de patrimônio. Ao caracterizar-se como um bem ambiental, os instrumentos estabelecidos pela Lei $n^{\circ}$ 6.938/198 aplicam-se ao patrimônio arqueológico.

Somadas a eles, aplicam-se, ainda, todos os outros instrumentos legais advindos de normas administrativas, de legislações específicas (como a Lei n $\left.{ }^{\circ} 3.924 / 1961\right)$ e da legislação ambiental. Há de se destacar, ainda, que a CF/1988 recepcionou a guarda e proteção a todos os sítios arqueológicos, inclusive os que ainda não foram identificados. Por conta dessa proteção ampliada, Soares (2007) define o patrimônio arqueológico como um bem de proteção qualificada. Com base em Dantas (2015), ao ter a União como a sua titular, ele é também um bem público inalienável e imprescritível. Dessa maneira, para a gestão do patrimônio arqueológico, a legislação estabelece um sistema de cogestão que agrega instituições federais, arqueólogos(as), instituições de guarda e empreendedores. Tudo isso a fim da otimização de ações para o melhor conhecimento, preservação e promoção do bem.

Conforme consta nas linhas do $\int 1^{\circ}$ do art. 216 da CF/1988, a promoção e proteção do patrimônio cultural brasileiro é atribuição do "[...] Poder Público, com a colaboração com a comunidade [...]" (BRASIL, 1988). Portanto, o dever de proteção dos bens culturais - dentre eles os bens arqueológicos - é estendido à sociedade. Destarte, “[...] tanto o Estado quanto a sociedade, compreendendo também os indivíduos em sua atuação particular, têm deveres para com o patrimônio cultural [...] (CUNHA FILHO; RABÊLO, 2018, p. 96). A imposição do dever de defender e preservar o meio ambiente para as presentes e futuras gerações (art. 225), assim como a conceituação do bem cultural como portador de referência à memória, à identidade e à ação da sociedade brasileira (art. 216), ofertam ao bens culturais a característica de bens de interesse público (SOARES; FARIAS, 2018).

Partindo dessa lógica, Soares e Farias (2018) ensinam que o tratamento dos bens culturais é apartado do regime de direito público e do regime de direito privado. Assim, o bem cultural é objeto de tutela jurídica que possui dois enfoques: dominialidade e fruição. A dominialidade funda-se no uso e gozo da propriedade em conformidade com os critérios normativos 
e é guiada pelo princípio da função social da propriedade. No que tange à fruição, cabe ao Estado, na condição de titular da situação jurídica do bem público, assegurar o acesso aos bens culturais e possibilitar a sua fruição a partir de uma perspectiva coletiva (SOARES, 2018).

A despeito desse leque protetivo denso, a proteção efetiva do patrimônio arqueológico ainda é frágil diante da implantação de empreendimentos estruturais com forte carga política e econômica. Para além do desconhecimento do patrimônio cultural como um direito fundamental difuso e do patrimônio arqueológico como um bem ambiental cultural de proteção qualificada, compreende-se que essa fragilidade também decorre da tradição colonialista interna que negligenciou os direitos e a memória dos povos originários, a partir do surgimento dos Estados-Nação, nesta parte do globo terrestre, conforme assevera Oliveira (2015). Dentro dessa lógica e sob influências do modelo histórico-cultural, o fazer tradicional da Arqueologia corroborou para uma violência epistêmica, em que tais povos foram presos a um passado distante do tempo presente, relegados "[...] ao tempo dos selvagens primitivos [...]" (OLIVEIRA, 2015, p. 361).

Nesses termos, parafraseando o autor, a implantação de projetos desenvolvimentistas tem sido delineada por um sistema estruturante

[...] caracterizado por relações sociais e de poder, leis, práticas, burocracias e saberes que caracterizam formas de exploração, dominação e manutenção de assimetrias por parte das elites nacionais contra coletivos étnica e culturalmente distintos em relação a si ou à maioria da população (OLIVEIRA, 2015, p. 361).

Entende-se do autor que a dinâmica desse sistema estruturante configurou a percepção do patrimônio arqueológico, principalmente o referente ao passado indígena pré-colonial, como algo cuja proteção e interesse diz respeito apenas ao Estado, não importando aos povos originários no tempo presente, nem tampouco à coletividade.

Nesses termos, a exemplo dos estudos de Gnecco e Dias (2015), no âmbito da arqueologia feita para fins de licenciamento ambiental, se tem a existência de uma articulação com a lógica da modernidade e do capitalismo. Para os autores, além de fragilizar a relação entre arqueologia e antropologia, essa articulação limita as oportunidades da arqueologia na reconstrução de seu mecanismo metafísico e ontológico (marcado pela hierarquia e neocolonialidade), reduzindo o caráter crítico dessa ciência diante da ordem global. Na Amazônia, estudos diversos (CASTRO et al., 2014; SANTOS, 2017; SIMONIAN; COSTA; BAPTISTA, 2013; SIMONIAN; BAPTISTA, 2015) evidenciam que a lógica desenvolvimentista tem pressionado populações locais e provocado processos de expropriação, espoliação e insustentabilidade nos aspectos humano e ambiental.

No que tange à arqueologia, essa mesma lógica tem somado para que se negligenciem os direitos de povos indígenas e populações locais. Os estudos de Oliveira (2015) e Fausto (2015) trazem exemplos nítidos desse fenômeno. Ao ter-se em vista os prejuízos culturais e socioambientais desse cenário, é mister a reflexão acerca da função social da arqueologia e do patrimônio arqueológico. Nessa esteira, acompanhando a defesa de Castañeda (2008), há de se reconhecer que a arqueologia é um fenômeno sociocultural e que, encarada desse modo, ela pode aglutinar forças para a defesa dos direitos fundamentais de populações atingidas por projetos de desenvolvimento que negligenciam as prerrogativas constitucionais que amparam os interesses coletivos.

PRACS: Revista Eletrônica de Humanidades do Curso de Ciências Sociais da UNIFAP 
Dito isto, avalia-se a urgência de duas frentes para a construção de um cenário mais democrático e menos colonialista na gestão do patrimônio arqueológico. A primeira é emprestada do raciocínio de Silva (2007) e diz respeito ao acolhimento - por parte daqueles que planejam e executam políticas públicas - da compreensão de que a preservação patrimonial não é feita apenas com a aplicação de leis. Com base nas palavras da autora:

[...] as regras ligadas à preservação arqueológica se inserem num quadro muito mais amplo de políticas públicas que devem ser fundamentadas nas reivindicações da coletividade, da sociedade. É ela quem deve acionar o aparelho estatal para que este venha proteger os elementos que julga serem de seu interesse (SILVA, 2007, p. 71).

Pari passu a primeira e inspirada na defesa de Salerno (2012), a segunda frente diz respeito à construção de uma nova agenda política da arqueologia nos países do sul. Uma agenda cujas práticas sejam consonantes com os princípios da arqueologia pública, ou seja, ações capazes de desencadear processos de negociação e criação de sentidos em torno da materialidade arqueológica. Nos termos de Gnecco (2010), ações como estas são aberturas valiosas para a entrada da ética e da justiça social no âmbito da arqueologia. Viabilizam, portanto, o desprendimento da disciplina em relação ao passado, podendo estabelecer conexões com o presente e o futuro de coletivos humanos situados no entorno de sítios arqueológicos. O que, por sua vez, fortalece a função social da arqueologia enquanto ciência.

\section{O CASO DO Sítio DA PONTE BINACIONAL E OS DESAFIOS DA EDUCAÇÃO PATRIMONIAL}

Distante da capital (Macapá) cerca de 600 quilômetros, o município de Oiapoque está situado no extremo norte do estado do Amapá, na fronteira entre o Brasil e a Guiana Francesa. Segundo o último censo realizado pelo IBGE, Oiapoque possui aproximadamente 20.426 habitantes, que se distribuem na sede do município (a cidade de Oiapoque), nos distritos de Clevelândia do Norte $^{7}$ e Vila Velha ${ }^{8}$, bem como ao longo das três terras indígenas situadas no território, a saber: Juminã, Uaçá e Galibi. O município abrange, ainda, o Parque Nacional do Cabo Orange (PNCO), primeira unidade de conservação federal criada no Amapá, cuja proporção é de 619.000 hectares em um perímetro de aproximadamente 590 quilômetros.

Com uma ocupação humana que remonta ao período pré-colonial, por séculos, as populações desse território estiveram envolvidas em conflitos territoriais motivados, sobretudo, pelo desejo de exploração dos recursos naturais. Com uma sociodiversidade riquíssima e com um contexto ambiental privilegiado, ao longo dos séculos, o território do município tem sido palco da construção de uma rede de intercâmbio étnico que incrementou a diversidade cultural dos povos da região (LÓPES GARCÉS, 2011). Estudos arqueológicos recentes permitem o entendimento de que essa diversidade cultural mergulha no tempo e sinaliza a complexidade cultural dos povos antigos da região, notadamente expressa nas características dos sítios da fase Aristé (SALDANHA; CABRAL, 2014).

De acordo com Silva (2013), o projeto da Ponte Internacional sobre o rio Oiapoque, doravante chamado Ponte Binacional, faz parte dos projetos geopolíticos de integração nacio-

7 Área militar do Exército brasileiro.

8 Área agroextrativista. 
nal com os países da Pan-Amazônia e do Mercosul. Conforme o autor, o empreendimento objetiva interligar fisicamente o Brasil com a Guiana Francesa, o Suriname e a Guiana. Nos termos de Silva (2013), essa conexão física se realizará por meio da rodovia Transguianense e viabilizará: i) o aproveitamento do Porto de Santana/AP por outros países para fins de intercâmbio comercial; ii) a utilização da BR-156 para o fomento do potencial turístico do estado do Amapá; iii) a minimização de problemas de infraestrutura e a melhoria no trânsito de mercadorias e pessoas.

Isto posto, atualmente, no contexto regional, nacional e internacional, o projeto da Ponte Binacional ligando o Brasil à Guiana Francesa destaca-se pela sua relevância nos aspectos políticos e econômicos. Segundo indica o Programa Arqueológico de Prospecção, Resgate e Educação Patrimonial da Ponte Internacional sobre o rio Oiapoque ${ }^{9}$, os estudos concernentes à etapa de elaboração do diagnóstico arqueológico para o licenciamento ambiental do empreendimento indicaram o alto potencial da área para a ocorrência de vestígios arqueológicos relativos ao período pré-colonial e histórico. Nos termos do documento:

[...] na área que seria diretamente afetada pelo empreendimento foram identificadas duas ocorrências de vestígios arqueológicos [...] um sítio multicomponencial (histórico e indígena), com grandes dimensões e elevada relevância científica. O outro, se referia a um fragmento cerâmico (possivelmente indígena) encontrado em um pequeno acesso vicinal próximo à lateral do acesso à BR-156. Apesar de pontual, indicava a incidência de outras ocupações ou de atividades periféricas relacionadas ao sítio em questão, potencializando zonas próximas a drenagens de entorno situadas no contexto de inserção do empreendimento (PROGRAMA, 2009, p. 5)

De acordo com o documento evidenciado, feita a constatação, em janeiro de 2008, a empresa A Lasca Consultoria e Assessoria em Arqueologia ${ }^{10}$ informou ao IPHAN e ao DNIT11 a respeito da existência de sítios arqueológicos na área. A partir de então, criou-se o Programa Arqueológico de Prospecção, Resgate e Educação Patrimonial da Ponte Internacional sobre o rio Oiapoque, cujo objetivo foi a "[...] prevenção dos impactos negativos identificados sobre o patrimônio arqueológico, decorrentes da implantação do empreendimento” (PROGRAMA, 2009, p. 5).

Sob a coordenação técnica de Lúcia de Jesus Cardoso Oliveira Juliani, o programa foi autorizado pela Portaria IPHAN no 41, de 16 de dezembro de 2008. Entretanto, por motivo não identificado, o empreendedor responsável pela obra (DNIT) não providenciou a contratação da equipe responsável pela elaboração do programa arqueológico da área (PROGRAMA, 2008). Desse modo, em agosto de 2009, aparentemente ignorando a necessidade de efetivação do programa arqueológico criado para minimizar os impactos da obra sobre o patrimônio arqueológico lá contido, é iniciada a movimentação de máquinas no canteiro de obras.

Ao saber da movimentação e já ciente da existência de sítios na área, o IPHAN solicitou à representação do IBAMA em Oiapoque a imediata interdição da obra. Com os serviços de construção da ponte paralisados, o caso da Ponte Binacional passou a ter uma forte cobertura da mídia, a qual especulou assuntos diversos, tais como: os motivos da paralisação da obra; a data de retomada da construção; e, inclusive, a importância dos sítios diante do re-

\footnotetext{
${ }^{9}$ A cópia do documento citado foi cedida aos autores pelo NUPArq/IEPA, instituição que concedeu apoio institucional para os estudos arqueológicos da Ponte Binacional.

10 Responsável pelos estudos arqueológicos preliminares da área.

11 Departamento de Infraestrutura e Transporte, responsável pelo empreendimento.
} 
torno econômico do empreendimento. Em face da repercussão das notícias, na época, gerou-se uma forte comoção pública no Amapá, posto que a conexão física com a Guiana Francesa é considerada uma importante estratégia de desenvolvimento para o estado.

Diante da repercussão e dos interesses políticos e econômicos envolvidos no caso, o Governo do Estado do Amapá (GEA) enviou para Oiapoque a equipe de arqueologia do NUPArq/IEPA, a qual passou a fornecer apoio institucional para o resgate arqueológico do empreendimento, uma vez que, até então, o DNIT não havia providenciado a contratação da equipe da A Lasca Arqueologia, responsável pelos estudos arqueológicos. Com base nas informações do relatório de campo, os trabalhos de resgate do sítio foram realizados no período de 25 de agosto a 18 de setembro de 2009. Nesse período, a equipe da A Lasca Arqueologia já havia chegado ao local, de modo que o resgate foi feito em parceria por essa empresa e o NUPArq/IEPA, que continuou ofertando apoio técnico às atividades (PROGRAMA, 2009).

Sobre a situação encontrada, o documento descreve o seguinte:

[...] foi identificada uma série de danos [...], tais como a abertura de acessos sobre o sítio, a remoção de parte da camada arqueológica no platô alto do morro do sítio, além de movimentação intensa de terra em áreas não prospectadas em sub-perfície (PROGRAMA, 2009, p. 55).

A área total pesquisada pelas equipes da A Lasca Arqueologia e do NUPArq/IEPA no sítio Oiapoque $1^{12}$ correspondeu a aproximadamente $2.000 \mathrm{~m}^{2}$. Conforme dados do Programa Arqueológico (2009), essa dimensão permitiu a identificação de dois componentes diferentes: um ameríndio pré-contato e um do período histórico, que provavelmente é de fins do século XVIII ou início do século XIX, tal como infere a louça encontrada.

Segundo o documento aqui explorado, a escavação do sítio Oiapoque 1 viabilizou a visualização total de uma casa lá situada, a qual era formada parcialmente por paredes de pedra e tijolo e também parcialmente por paredes de madeira. A escavação revelou, ainda, a distribuição de estruturas arqueológicas de uma antiga aldeia indígena, o que permitiu a delimitação de casas, de fossas, poços e de áreas onde os antigos habitantes do lugar realizam o sepultamento de seus antepassados (PROGRAMA, 2009, p. 100).

A escavação revelou uma quantidade elevada de material arqueológico, que seguiu para a reserva técnica do NUPArq/IEPA, local em que está sendo analisado. A parte do sítio não afetada foi preservada. Há planos para a criação de um possível museu a céu aberto para proporcionar a educação patrimonial. Expostos os fatos que provocaram a interdição inicial da obra, bem como expostos alguns dos resultados das escavações realizadas na área da Ponte Binacional, fica nítida a dificuldade de efetivação da proteção do patrimônio arqueológico em meio a projetos de infraestrutura. Viu-se que, apesar da existência de uma extensa base legal, o patrimônio arqueológico fica vulnerável à destruição quando está diante de projetos imersos em interesses políticos e econômicos.

Sobre o assunto, com base em Caldarelli (2007, p. 153), reforçar-se que, em se tratando da opção pelo salvamento de sítios arqueológicos de seu lugar de origem, a preservação in situ deve ser "[...] sempre a melhor alternativa [...] sendo o salvamento um mal necessário, ao qual se deve recorrer unicamente na ausência de outra opção que salvaguarde o bem [...]" (CALDARELLI, 2007, p. 153). No caso do sítio da Ponte Binacional, sabe-se que as condi-

12 Nome de registro do sítio, cujas coordenadas são: UTM 22N 408.340E / 426.090N (datum SAD 69). 
ções do terreno não permitiram a mudança do projeto original, o que justifica a opção pelo salvamento dos elementos que sobreviveram à destruição inicial do sítio. Contudo, há de se reconhecer que, ao optar pelo início das obras sem o cumprimento efetivo do estudo arqueológico da área, o DNIT inviabilizou um debate coletivo acerca dos interesses e prioridades da sociedade para com o passado guardado nos elementos do sítio arqueológico da Ponte Binacional.

Fragilidades como esta revelam a necessidade do fortalecimento das políticas e instituições públicas responsáveis pela gestão do patrimônio arqueológico no Amapá. É necessário que a produção científica em torno do patrimônio arqueológico ultrapasse os muros da academia para, assim, alcançar a sociedade. É necessário que os interesses e prioridades da sociedade sejam considerados por meio de instrumentos democráticos de consulta. É necessário que o Poder Público observe nas políticas de preservação patrimonial o exercício da cidadania.

Por fim e não menos importante, é necessária a percepção de que políticas públicas de preservação cultural não se fazem apenas com leis. Como sabiamente ensina Silva (2007, p. 71), "[...] ações embasadas em determinações legais devem ser vistas como um último recurso de um processo que se inicia com a educação patrimonial". A educação é uma das mais eficazes estratégias de proteção e promoção do patrimônio cultural, uma vez que, por meio dela, a sociedade pode (re)conhecer seus bens culturais, criando ou fortalecendo laços de pertencimento.

Como orienta o IPHAN (2014), a educação patrimonial constitui todos os procedimentos educativos formais e não formais, cuja finalidade seja a colaboração para o reconhecimento, a valorização e a preservação dos bens culturais; ela deve viabilizar a participação efetiva dos coletivos detentores e produtores de referências culturais, os quais possuem noções diversificadas de patrimônio cultural. No que tange ao patrimônio arqueológico, a educação patrimonial pode permitir a inclusão de narrativas locais à gestão desse bem. Assim, pode somar para a construção de uma plataforma de negociação de alteridades dos coletivos da Amazônia.

\section{CONSIDERAÇÕES FINAIS}

A Ponte Binacional sobre o Rio Oiapoque é elemento importantíssimo para o desenvolvimento socioeconômico do estado do Amapá. Não é intenção deste artigo a negação disso. O texto aqui desenvolvido procurou propor reflexões para o fortalecimento das políticas públicas que tratam da proteção do meio ambiente cultural.

Em um Estado em que os grandes projetos de infraestrutura são presentes desde a década de 1950, é necessário que se oportunizem debates que tratem não apenas dos benefícios advindos desses projetos; questionamentos a respeito dos possíveis danos desses empreendimentos sobre o meio ambiente cultural também devem ter vez. O patrimônio arqueológico da Amazônia é um bem frágil e não renovável. Permitir a total destruição dele para a execução de grandes projetos é, no mínimo, repetir a história que negou o pertencimento do homem da Amazônia à dinâmica da região.

Estradas e pontes são essenciais para a promoção do desenvolvimento da região, porém, esse desenvolvimento não pode se dar às custas da destruição do patrimônio arqueológico local. Que a interdição de obras, a fim de resguardar esses bens seja feita quantas vezes for

PRACS: Revista Eletrônica de Humanidades do Curso de Ciências Sociais da UNIFAP 
necessária. Contudo, para além das ações de intervenção, o que se quer é que os processos de licenciamento ambiental ocorram conforme os dispositivos legais e viabilizem a participação democrática da sociedade, de modo a acolher seus anseios e prioridades.

\section{REFERÊNCIAS}

AMARAL, A. [et al.]. Do lado de cá: fragmentos de História do Amapá. Belém: Açaí, 2011. BALÉE, W. The culture of Amazonian forest. In: POSEY, D. A.; BALÉE, W. (Ed.). Resource management in Amaronia: indigenous and folk strategies. New York: New York Botanical Garden, 1989, p. 1-21.

BARRETO, M. V. Abordando o passado: uma introdução à Arqueologia. Belém: Paka-Tatu, 2010.

BRASIL. Constituição da República Federativa do Brasil de 05 de outubro de 1988.

CALDARELLI, S. B. A preservação do patrimônio cultural em planejamento ambiental. In: Anais do $4^{\circ}$ Encontro Nacional de Estudos Sobre o Meio Ambiente, 1993, 2: 258-265. Cuiabá, UFMT.

CASTANEDA, Q. E. The "Ethnographic Turn" in Archaeology: research positioning and reflexivity in Ethnographic Archaeologies. In: Castaneda, Q.E. \& Matthews, C.N. (eds.) Ethnographic Archaeologies: reflections on stakeholders and archaeological practices. Altamira Press, 2008, p. 25-61.

CASTRO, E. R. et al. Hidrelétricas na Amazônia e grandes dilemas postos à sociedade no século XXI. Paper do NAEA, n. 343, 2014, p. 1-26.

CUNHA FILHO, F H.; RABÊLO, C. N. O caráter multiforme, ubíquo e multiconcorrencial da vigilância sobre o patrimônio cultural brasileiro. In: SOARES, I. V. P.; PRAGMÁCIO, M. (Org.). Tutela jurídica e política de preservação do patrimônio cultural imaterial. Salvador: Editora JusPodivm, 2018, p. 87-106.

DANTAS, F. S. O patrimônio cultural protegido pelo Estado Brasileiro. In: CAMPOS, J. B.; PREVE, D. R.; SOUZA, I. F. (Org.). Patrimônio cultural, direito e meio ambiente: um debate sobre a globalização, cidadania e sustentabilidade. Curitiba: Multideia, 2015. p. 31-53.

FAUSTO, Carlos. Da responsabilidade social de antropólogos e arqueólogos: sobre contratos, barragens e outras coisas mais. Revista de Arqueologia, v. 28, n. 2, 2015, p. 202-215.

GNECCO, C. Da arqueologia do passado à arqueologia do futuro: anotações sobre multiculturalismo e multivocalidade. Amazônica, v. 2, n. 1, p. 92-103, 2010.

IPHAN. Educação Patrimonial. Histórico, conceitos e processos. Brasília: IPHAN, 2014. LEITE, J. R. M. Introdução ao conceito jurídico de meio ambiente. Belo Horizonte: Del Rey, 1998, p. 51-70.

LÓPEZ GARCÉS, C. L. Pueblos indígenas, fronteras y estados nacionales: reflexiones histórico-antropológicas desde las fronteras Brasil-Colombia-Perú y Brasil-Francia. Revista Mundo Amazónico, Leticia Co., Instituto Amazónico de Investigaciones (IMANI), v. 2, p. 155-178, mar. 2011.

MEGGERS, B. Amazônia, a ilusão de um paraíso. São Paulo: Edusp, 1987.

MIRANDA, M. P. de S. Tutela do Patrimônio Cultural Brasileiro: Doutrina, Jurisprudência, Legislação. Belo Horizonte: Del Rey, 2006.

NEVES, E. G. Arqueologia da Amarônia. Rio de Janeiro: Jorge Zahar, 2006.

NUNES FILHO, E. P. Modelo de desenvolvimento local na Amazônia Pré-Colonial: com- 
plexidade cultural e modernidade em sociedades pré-coloniais da Amazônia. Estação Científica, UNIFAP. Macapá, v. 1, n. 2, p. 99-109, 2011.

OLIVEIRA, J. E. de. Arqueologia de contrato, colonialismo interno e povos indígenas no Brasil. Amazônica v. 7, n. 2, 2015, p. 354-374.

PROGRAMA Arqueológico de Prospecção, Resgate e Educação Patrimonial Ponte Internacional sobre o rio Oiapoque, na BR-156. Município de Oiapoque-AP. Portaria: IPHAN No 41, de 16 de dezembro de 2008. Processo IPHAN no 01492.000346/2008-41. Relatório de Campo. Coordenação Técnica: Ms. Lúcia J. C. Oliveira Juliani. Dezembro de 2009.

ROOSEVELT, A. C. Arqueologia da Amazônia. In: CUNHA, M. C. da. (Org.). História dos indios no Brasil. São Paulo: EDUSP, 1992. p. 53-86.

SALDANHA, J. D. M.; CABRAL, M. P. A longa história indígena na costa norte do Amapá. Anuário Antropológico, v. 39, n. 2, 2014, p. 99-114.

ALERNO, V. M. Pensar la arqueologia desde el sur. Complutum, v. 23, n. 2, p. 191-203, 2012.

SANTOS, R. S. A construção da rodovia BR-153 na fronteira e urbanização da cidade de Araguaína, Tocantins. Novos Cadernos NAEA. V. 20, n.3, 2017, p. 97-114.

SILVA, G. de V. Desenvolvimento econômico em cidades da fronteira amazônica: ações, escalas e recursos para Oiapoque-AP. Confins, 17, 2013.

SILVA, R. C.P. Os desafios da proteção legal: uma arqueologia da Lei no 3.924/1961. Revista do Patrimônio Histórico e Artístico Nacional; Patrimônio Arqueológico: o desafio da preservação, no 33, 2007, p. 59-73.

SIMONIAN, L. T. L.; BAPTISTA, E. R. A formação socioambiental da Amazônia. Belém: NAEA/UFPA, 2015.

SIMONIAN, L. T. L.; COSTA, Arley José Silveira da.; BAPTISTA, Estér Roseli. (Org). Escudo Guianês, biodiversidade, conservação dos recursos naturais e cultura. Belém: NAEA-UFPA; GSF, 2013, 469 p.

SOARES, I. V. P. S. Proteção jurídica do patrimônio arqueológico no Brasil: fundamentos para efetividade da tutela em face de obras e atividades impactantes. Erechim: Halibis, 2007.

SOARES, I. V. P. S.; FARIAS, T. Patrimônio cultural imaterial no licenciamento ambiental. In: SOARES, I. V. P.; PRAGMÁCIO, M. (Org.). Tutela jurídica e política de preservação do patrimônio cultural imaterial. Salvador: Editora JusPodivm, 2018, p. 145-182. 